\title{
SOlIDARIEDADE E EDUCAÇÃO NO PROJETO AMIGOS DA ESCOLA: A ÓPTICA DAS PROPOSTAS EDUCACIONAIS NEOLIBERAIS*
}

\author{
Alexandre Shigunov Neto, \\ da Faculdade Central de Cristalina \\ Lizete Shizue Bomura Maciel, \\ da Universidade Estadual de Maringá
}

Resumo: o objetivo deste texto é o de apresentar uma discussão preliminar sobre o Projeto Amigos da Escola. O projeto, que teve início em 1999, é uma iniciativa da Rede Globo de Televisão, que o desenvolveu concomitantemente com o Projeto Brasil 500 Anos e o Comunidade Solidária, e destina-se a fortalecer a participação comunitária no esforço de melhoria da escola pública. Nesse sentido, pretende-se nesta análise preliminar questionar três aspectos, que se desdobram em inúmeros outros também de extrema importância, e ponderar sobre eles, pois são fundamentais para a compreensão do projeto hegemônico neoliberal, que se consolidou em torno do tema solidariedade vinculado às questões educacionais: a tentativa do Estado de eximir-se de suas obrigações, repassando à comunidade a responsabilidade pelo funcionamento e manutenção da escola pública; a tentativa de privatização da escola pública, sob o argumento da falta de qualidade e do alto custo em relação ao benefício que proporciona para a população; a tentativa de denegrir a imagem dos profissionais da educação que atuam nas escolas públicas, bem como de questionar sua necessidade e função nas instituições escolares públicas, com a conclamação dos cidadãos para suprir as funções daqueles profissionais.

Palavras-chave: Neoliberalismo e Educação. Projeto Amigos da Escola. Qualidade da escola.

\footnotetext{
* Artigo recebido em 09/09/2010 e aprovado em 20/10/2010.
} 


\section{CONSIDERAÇÕES INICIAIS}

Pretende-se nesta análise preliminar questionar três aspectos, que se desdobram em inúmeros outros também de extrema importância, e ponderar sobre eles, pois são fundamentais para a compreensão do projeto hegemônico neoliberal que se consolidou em torno do tema solidariedade vinculado às questões educacionais:

- a tentativa do Estado de eximir-se de suas obrigações, repassando à comunidade a responsabilidade pelo funcionamento e manutenção da escola pública;

- a tentativa de privatização da escola pública, sob o argumento da falta de qualidade e do alto custo em relação ao benefício que proporciona para a população;

- a tentativa de denegrir a imagem dos profissionais da educação que atuam nas escolas públicas, bem como de questionar sua necessidade e função nas instituições escolares públicas, com a conclamação dos cidadãos para suprir as funções daqueles profissionais.

Portanto, nossas reflexões sobre o "Projeto Amigos da Escola" perpassarão pela questão do neoliberalismo aplicado às questões educacionais.

A importância do presente texto pode ser compreendida na medida em que se consideram ainda em voga as propostas neoliberais aplicadas à educação, existindo, assim, a necessidade da compreensão de que tais propostas compõem projetos mais amplos. Há, portanto, a necessidade de superação da visão parcial e naturalizada desse complexo processo. Assim sendo, faz-se necessário desvendar seu significado, suas implicações na formação do trabalhador-cidadão e os rumos que tais propostas impingem à sociedade.

\section{AS POLÍTICAS EDUCACIONAIS NEOLIBERAIS}

A temática das políticas educacionais neoliberais adquiriu importância crescente, sobretudo a partir da década de 1980, com a proliferação pelo mundo, enquanto projeto hegemônico, dos ideais neoliberais. As políticas neoliberais, que têm como princípios fundamentais a livre concorrência do mercado e a não-intervenção do Estado na economia, desencadearam inúmeras situações adversas, principalmente nos países em desenvolvimento.

Essas políticas tiveram seu surgimento nos anos 1970, com a crise do estado de bem-estar social e dos regimes social-democratas, em virtude de diversos fatores sociais, econômicos e políticos, tais como: a progressiva 
saturação dos mercados internos de bens de consumo duráveis; a concorrência intercapitalista; a crise fiscal e inflacionária, que provocou a retração dos investimentos. Em decorrência dessa impossibilidade de resposta aos problemas surgidos, a economia volta novamente a seguir o modelo baseado nas leis naturais do mercado ${ }^{1}$, por intermédio das políticas neoliberais, que pregam: o estado mínimo, o fim da estabilidade no emprego, o corte abrupto das despesas previdenciárias e dos gastos em geral com as políticas sociais. (SHIGUNOV NETO; MACIEL, 2004)

Os pressupostos teóricos das propostas neoliberais estão presentes no liberalismo, na Escola Austríaca ${ }^{2}$, da qual faziam parte Ludwig von Mises ${ }^{3}$ e Friedrich August von Hayek ${ }^{4}$, e na Escola de Chicago ${ }^{5}$, com Milton Friedman', seu ilustre associado.

O livro de Friedrich August von Hayek intitulado O caminho da servidão pode ser considerado a fonte e inspiração teórica e ideológica das propostas neoliberais, ou seja, constitui-se a cartilha do neoliberalismo. Portanto, podemos atribuir a paternidade do neoliberalismo a Hayek.

Ao assumir um caráter de projeto hegemônico e de ampla divulgação, ao ponto de tornar-se senso comum entre a população, a temática dos ideais neoliberais, de forma geral, e a qualidade total na educação, em específico, têm sido alvo de inúmeras pesquisas e publicações por parte de pesquisadores nacionais ao longo das últimas duas últimas décadas do século passado e desses primeiros anos do século XXI, a saber: Gentili; Silva (1999), Sader; Gentili (1995), Azevedo (1995), Carrion; Vizentini (1997) Comblin (2001), Shigunov Neto; Maciel (2004) e Shigunov Neto (2011). Também pesquisadores internacionais, dentre os quais destacamos: Estêvão (1998, 2000, 2002), Gentili (1998 e 2000), Pacheco (2000), Passet (2002) e Santomé (2003) vêm, há algum tempo, desenvolvendo pesquisas com o intuito de desmistificar a temática, repleta de ambiguidades, equívocos e ilusões,

Pelo rumo que tomaram na contemporaneidade, as políticas neoliberais são vistas por nossos governantes como políticas salvadoras que proporcionarão o tão esperado desenvolvimento do país, sem preocupação com o fato de que essas políticas pressupõem laços de subordinação, exigências da nova ordem social.

Em termos nacionais, poder-se-ia questionar o seguinte: com a posse do primeiro Governo Lula, em 2003, sofreram as políticas educacionais drásticas transformações, desvinculando-se das políticas educacionais neoliberais?

Acreditamos que, em termos de discurso, sim, mas em termos de ações e políticas educacionais, não. Portanto, ao invés do que poderíamos esperar, as políticas educacionais nacionais continuam a pautar-se pelo mo- 
delo neoliberal, que prega a não-intervenção do Estado no mercado, a livre concorrência no mercado, a política de quantidade e não de qualidade, os privilégios e concessões às instituições de ensino particulares e as propostas simplistas e de curto prazo.

O neoliberalismo enquanto projeto político, econômico, social e educacional de caráter hegemônico, fundamentado na subordinação absoluta da sociedade ao mercado livre e à não intervenção estatal, surgiu a partir de 1970 com a crise do estado de bem-estar social ${ }^{7}$ e sua incapacidade para resolver os graves problemas econômicos. Naquele momento, as propostas neoliberais ressurgem com força total e difundem-se como a única solução possível para a economia mundial sair da crise que havia se instaurado. Entre alguns dos motivos do grande impulso tomado pela ideologia neoliberal a partir de 1970 encontram-se: a crise dos anos 70, a incapacidade do estado de bem-estar social em resolver os graves problemas econômicos gerados por essa crise e a consagração de Frederick Hayek e Milton Friedman, que receberam, respectivamente em 1974 e 1976, o Prêmio Nobel de Economia. Nesse sentido, havia àquela época no mundo um clima ideológico, político e social propício para a implantação do neoliberalismo. (SHIGUNOV NETO, MACIEL,2004)

O primeiro governo a adotar explicitamente as propostas neoliberais como programa foi o de Margaret Thatcher, em 1979, na Inglaterra, seguido pelos Estados Unidos, de Ronald Reagan, em 1980, e pela Alemanha, em 1982, por meio do governo do primeiro-ministro Helmut Kohl. Entretanto, não demorou muito para que a retórica neoliberal se expandisse para os demais países europeus, para os países do Leste europeu e, posteriormente, para os países da América Latina. Dessa forma, como explica Pablo Gentili (1999), teve início o processo de construção hegemônica,

isto é, como uma estratégia de poder que se implementa em dois sentidos articulados: por um lado, através de um conjunto razoavelmente regular de reformas concretas no plano econômico, político, jurídico, educacional, etc. e, por outro, através de uma série de estratégias culturais orientadas a impor novos diagnósticos acerca da crise e construir novos significados sociais a partir dos quais legitimar as reformas neoliberais como sendo as únicas que podem (e devem) ser aplicadas no atual contexto histórico de nossas sociedades. (p. 9)

Na medida em que a crise econômica se agravava, a ideologia neoliberal se alastrava pelo mundo capitalista e se (re)afirmava como a única solução possível para todos os problemas da sociedade. Em virtude disso, sustentava-se que não haveria possibilidade de enfrentamento da crise a não 
ser por intermédio de sua proposta: a confiança incondicional na dinâmica do mercado como reguladora da economia do país; nesses termos, a ideologia neoliberal transformou-se em dogma.

Na América Latina, a ideologia neoliberal foi amplamente difundida, alastrando-se por uma grande quantidade de países como, por exemplo: México em 1988, no governo do presidente Salinas; Argentina, em 1989, com o presidente Carlos Menem; Venezuela, em 1989, no governo do presidente Carlos Andrés Perez. No Brasil, quem acolheu a ideologia neoliberal foi o presidente Fernando Collor de Melo. As propostas neoliberais foram adotadas também no Chile e no Peru.

No caso específico do Brasil, o maior exemplo de programas neoliberais encontra-se na administração de Fernando Henrique Cardoso, quando foram implementados alguns projetos, dentre os quais destacam-se: Programa Avança Brasil, os programas de privatizações de empresas públicas; o Bolsa Alimentação, o Bolsa Escola, Sociedade da Informação. Também no âmbito da iniciativa privada, encontram-se projetos de caráter neoliberal, como o Projeto Educacional Amigos da Escola, que é uma iniciativa da Rede Globo de Televisão, que o desenvolve juntamente com o Projeto Brasil 500 Anos, e o Comunidade Solidária, que se destina a fortalecer a participação comunitária no esforço de melhoria da escola pública.

O neoliberalismo é um projeto político, econômico e social de caráter hegemônico que está fundamentado na subordinação absoluta da sociedade ao mercado livre e na não intervenção estatal, portanto, nos pilares teórico-metodológicos da proposta neoliberal: desestatização, desregulamentação e desuniversalização.

O ideário neoliberal teoriza que o mercado livre é o elemento regulador de toda a sociedade, ou seja, verifica-se o fetiche do mercado como a panaceia para todos os problemas econômicos e sociais. (SHIGUNOv Neto; MACIEL, 2004, p. 44)

A implantação das propostas neoliberais implicou consequências de ordem social, tais como o agravamento das desigualdades sociais; exclusão e segmentação social; aumento da pobreza; aumento do desemprego; crescimento da miséria, da fome e da marginalidade econômica; desvio crescente de recursos para a especulação; incapacidade crescente de absorção de mão-de-obra e do trabalho humano; incapacidade de recuperar e sustentar ritmos elevados de crescimento. Portanto, as políticas neoliberais e a reestruturação produtiva alteraram de modo significativo a organização da produção, a política de emprego, o mercado de trabalho, os sindicatos. Contudo, e apesar de as implicações sociais serem negativamente fortes e com 
grande impacto sobre os trabalhadores, a ideologia neoliberal está sustentada no poder que lhe foi outorgado pelo povo. Ou seja, está amparada pelo desejo do povo que a colocou no poder e a mantém apesar das insatisfações. (Shigunov Neto, Maciel, 2004)

Nesses termos, pode-se inferir que o neoliberalismo nada mais é do que um conjunto de receitas econômicas e programas políticos. O discurso neoliberal, enquanto projeto hegemônico, propõe amplas reformas nos planos econômico, fiscal, político, social e educacional, com base nos pilares teórico-metodológicos da proposta neoliberal - desestatização, desregulamentação e desuniversalização.

O pressuposto neoliberal aplicado à educação fundamenta-se, essencialmente, sobre dois aspectos: a pressuposição de que a instituição escolar possa ser tratada igualmente a uma organização empresarial com fins lucrativos, a idéia do mercado educacional livre e sem a interferência estatal, e a transposição de conceitos aplicados no setor empresarial para a área educacional.

Para Gentili (1999), o discurso hegemônico neoliberal adotou como estratégia no campo educacional a proposição de

transferir a educação da esfera dos direitos sociais à esfera do mercado. A ausência de um verdadeiro mercado educacional (isto é, a ausência de mecanismos de regulação mercantil que configurem as bases de um mercado escolar) explica a crise de produtividade da escola. Para os neoliberais, o reconhecimento desse fato permite orientar uma saída estratégica mediante a qual é possível conquistar, sem "falsas promessas", uma educação de qualidade e vinculada às necessidades do mundo moderno: as instituições escolares devem funcionar como empresas produtoras de serviços educacionais. A interferência estatal não pode questionar o direito de livre escoIha que os consumidores de educação devem realizar no mercado escolar. Apenas um conglomerado de instituições com essas características pode obter níveis de eficiência baseados na competição e no mérito individual. (GENTILI, 1999, p. 28-29)

A privatização das escolas públicas, um dos pilares de sustentação da ideologia neoliberal, ganha força na medida em que argumenta a suposta eficiência das instituições privadas e a ineficiência intrínseca das instituições públicas, cerceadas por vícios e defeitos.

Na perspectiva neoliberal, os sistemas educacionais latino-americanos enfrentam hoje, basicamente, uma crise de eficiência, eficácia e produtividade, mais do que uma crise de universalização e de extensão dos serviços oferecidos. A expansão acelerada da oferta educacional, durante a 
segunda metade do século produziu-se, segundo esse argumento, sem que a mesma tenha sido acompanhada de uma distribuição eficiente dos recursos destinados ao setor e sem um controle eficaz da produtividade alcançada pelas instituições escolares. Dessa forma, interpreta-se que os sistemas educacionais latino-americanos cresceram quantitativamente sem garantir um consequente crescimento qualitativo. $O$ desafio da universalização, tendo sido cumprido, foi alcançado às custas de uma progressiva deterioração da qualidade e dos índices de produtividade das instituições escolares. A América Latina estaria enfrentando, assim, uma profunda crise de gerenciamento, de management das políticas educacionais. Em suma, uma profunda crise de qualidade. (GENTILI,1998, p. 16-17)

A escola não pode ser comparada a uma organização - industrial, comercial - pois apesar de possuir inúmeros elementos que lhe são próprios seus objetivos são divergentes. Primeiramente, fundamentalmente, via de regra, seu objetivo mor não é a obtenção do lucro. Entendemos que os princípios da qualidade até podem e devem ser aplicados à educação, mas muito diferentemente da aplicação que é dada às demais organizações, pois, basicamente, seus objetivos e sua estrutura são muito diferentes.

Os neoliberais afirmam que a crise da educação não é de democratização, pois esta já se processou no âmbito educacional, mas uma crise gerencial. Nesse sentido, sendo a crise de ordem gerencial, os neoliberais vislumbram uma reforma administrativa que visa a implementar instrumentos de regulação da eficiência, da produtividade e da eficácia.

A crise de qualidade expressa, por outro lado, a incapacidade gerencial do Estado para administrar os imensos e aparentemente ingovernáveis sistemas educativos nacionais. Trata-se de um complexo problema administrativo cuja solução não requer um aumento de recursos, mas uma destinação mais eficaz dos mesmos. Decorre disso que os governos neoliberais esforçam-se em enfatizar que a questão central não está em aumentar o orçamento educacional, mas em "gastar melhor"; que não faltam mais trabalhadores na educação, mas "docentes mais bem formados e capacitados"; que não faz falta construir mais escolas, mas "fazer um uso mais racional do espaço escolar"; que não faltam mais alunos, mas "alunos mais responsáveis e comprometidos com o estudo". Com os mesmos recursos financeiros, a mesma quantidade de professores e professoras, de alunos, de escolas e de salas de aulas, os governos neoliberais prometem fazer uma verdadeira revolução educacional. Para isso, dizem eles, precisa-se de uma condição inevitável: promover uma profunda reforma administrativa que reconheça que tão somente o mercado pode desempenhar um papel eficaz na destinação de recursos e na produção da informação necessária para a implementação de mecanismos competitivos meritocráticos que orientem os processos 
de seleção e hierarquização das instituições escolares e dos indivíduos que atuam nelas. (Gentili, 1998, p. 18-19)

Realmente, os objetivos exigidos pelas propostas neoliberais a escola tradicional não está apta a atingir. No entanto, são os objetivos a serem atingidos de acordo com as propostas neoliberais os melhores para a sociedade? Estão realmente preocupados com o bem-estar da sociedade? Com o desenvolvimento do país? Para poder satisfazer os objetivos dessas propostas, terá a escola que se "adaptar" à nova política, com uma nova estrutura, novos objetivos, enfim com uma total reformulação. Mas será que é disso que precisamos?

Os políticos e os projetos neoliberais, ao iludir-nos com propostas que aparentam ser em prol da sociedade e dos cidadãos, tentam denegrir a imagem e a utilidade da escola e da educação, atribuindo-lhes a ineficiência e os problemas resultantes dos modelos de produção capitalista. Na realidade, isso é um equívoco, porque não é função da educação formar mão-de-obra qualificada para a indústria, mesmo porque, com a introdução da maquinaria e de novas tecnologias, os empregos estão sendo extintos com grande velocidade. Formar trabalhadores para que trabalhos? Será esta a função que queremos para a educação?

A perspectiva gerencial sobre a questão da qualidade aparentemente estimula e valoriza não apenas a participação de pais, mães e alunos/as, mas também a de professores e professoras. Na verdade, entretanto, os procedimentos gerenciais da GQT, acoplados com a perspectiva neoliberal mais ampla da qual ela deriva, estão intrinsecamente ligados a mecanismos mais centralizados e padronizados de controle, regulação e governo. Em última análise, o objetivo da GQT é permitir uma comparação entre o desempenho das diferentes escolas que possibilite que seus consumidores efetuem uma escolha entre elas, com base na sua posição numa escala de classificação. É central a esse ranking não apenas a testagem padronizada de resultados de aprendizagem, mas também um controle padronizado do desempenho da força de trabalho docente. (SILVA, 1999, p. 178)

Pablo Gentili (1999), em seu texto Neoliberalismo e educação: manual do usuário, realiza uma análise do discurso neoliberal aplicado ao campo educacional. Por intermédio de uma abordagem crítica da proposta educacional neoliberal enquanto processo de construção hegemônica, questiona a forma neoliberal de pensar e projetar a política educacional.

Não há como utilizar-se das organizações com fins lucrativos para traçar o comparativo com as instituições de ensino. Do mesmo modo que as organizações sem fins lucrativos, as instituições públicas de ensino, e mesmo 
as instituições de ensino privado, apresentam como objetivo organizacional o bem-estar social e, na maioria dos casos, apresentam como resultados finais produtos não quantificáveis. Isto é, o produto final resultante dessas organizações visa a beneficiar a sociedade como um todo, com produtos sociais. Seu objetivo organizacional não é a obtenção de lucro, pelo que é inadmissível traçar um parâmetro de análise entre as organizações com fins lucrativos e as organizações sem fins lucrativos. Apesar disso, pode-se encontrar traços comuns a ambos os tipos de instituição: a gerência administrativa, a utilização de mão-de-obra especializada, a necessidade de recursos financeiros e materiais, a utilização de ferramentas da Administração de Marketing para promoção da organização. (SHIGUNov Neto; MAIIEL, 2004)

Prega-se a qualidade dos serviços educacionais. Assim, apregoa-se que não há falta de escolas e de professores, mas falta, sim, qualidade. Portanto, relegam-se as questões centrais, que deveriam ser priorizadas (questões pedagógicas), para um segundo plano, enquanto que as questões de cunho burocrático e administrativo vêm à tona.

Para os neoliberais, a crise em pauta expressa, nesses termos, a ineficiência do poder público para gerenciar eficiente e eficazmente o sistema educacional. Portanto, a intervenção estatal é prejudicial à concretização de uma educação de qualidade. Nesse sentido, um dos principais problemas ocasionados pela intervenção do poder público na educação é ter impossibilitado a criação de um mercado educacional livre - pressuposto básico da política hegemônica neoliberal.

Para concluir: estão em jogo, no momento, duas concepções radicalmente diferentes de qualidade em educação. Uma delas é tecnocrática, instrumental, pragmática, performativa, gerencial e se espelha nos objetivos e processos de trabalho da grande empresa capitalista. A outra é uma concepção política, democrática, substantiva, fundamentada em uma história de luta e de teoria e prática contra uma escola excludente, discriminadora e produtora de divisões, e a favor de uma escola e de um currículo que sejam substantiva e efetivamente democráticos. Uma educação de qualidade, numa perspectiva democrática, deve se concentrar nas estratégias e nos meios para proporcionar mais recursos materiais e mais recursos simbólicos para aqueles/as jovens e crianças que têm sua qualidade de vida e de educação diminuída não por falta de meios para medi-la, mas porque essa qualidade Ihes é negada, subtraída e confiscada. É irônico, paradoxal e revoltante que os mesmos grupos que lhes negam essa qualidade se concentrem em desenvolver procedimentos para medi-la e avaliá-la, quando nós já sabemos que essa qualidade é baixa porque a qualidade desfrutada por esses mesmos grupos é alta. Decidir qual concepção vai prevalecer é a nossa opção e é a nossa luta. (SILVA, 1999, p.187-188) 
Portanto, a eficiência do sistema educacional e a qualidade total na educação serão atingidas somente quando não houver mais a intervenção (malévola) do Poder Público e se consolidar o tão almejado mercado educacional.

Pablo Gentili (1998) apresenta uma análise das transformações educacionais promovidas pelo modelo neoliberal a partir da dinâmica hegemônica que as caracteriza enquanto reformas institucionais e como reformas culturais. A reforma cultural promovida pelos neoliberais visa a promover uma redefinição dos significados e sentidos atribuídos à atividade educacional e a implementar o processo de metamorfose das formas históricas de pensar as práticas educativas e a escola pública como esfera de concretização do direito social à educação:

trata-se, enfim, de transferir a educação da esfera da política para a esfera do mercado, negando sua condição de direito social e transformando-a em uma possibilidade de consumo individual, variável segundo o mérito e a capacidade dos consumidores. A educação deve ser pensada como um bem submetido às regras diferenciais da competição. Longe de ser um direito do qual gozam os indivíduos, dada sua condição de cidadãos, deve ser transparentemente estabelecida como uma oportunidade que se apresenta aos indivíduos empreendedores, aos consumidores "responsáveis", na esfera de um mercado flexível e dinâmico (o mercado escolar). A reforma administrativa proposta pelo neoliberalismo orienta-se a despublicizar a educação, a transferi-la para a esfera da competição privada. Reduzida à sua condição de mercadoria, a educação só deve ser protegida não por supostos direitos "sociais", mas pelos direitos que asseguram o uso e a disposição da propriedade privada por parte de seus legítimos proprietários. (GENTIL, 1998, p.19-20)

Nesses termos, para finalizarmos nossas reflexões sobre as propostas educacionais neoliberais recorremos ao professor Pablo Gentili (1999), para afirmar que o conceito de qualidade aplicado na sociedade capitalista não poderá transformar-se em direito de todos os homens, como afirmam os seguidores das propostas neoliberais, visto que na lógica de tal mercado a mercadoria de excelência destina-se a um grupo social reduzido, que pode pagar por ela. Portanto, a qualidade assim definida, onde quer que seja aplicada, destina-se a um grupo social seleto e não a todos os membros sociais, o que nos leva a três conclusões básicas: qualidade para poucos não é qualidade, é privilégio; a qualidade, reduzida a um simples elemento de negociação, a um objeto de compra e venda no mercado, assume a fisionomia e o caráter que define qualquer mercadoria: o acesso a ela é diferenciado e sua distribuição seletiva; em uma sociedade democrática e moderna, a qualidade da educação é um direito inalienável de todos os cidadãos, sem distinção. 


\section{A proposta do Projeto Amigos da Escola}

Após essa breve apresentação do projeto hegemônico neoliberal e de suas aplicações no campo educacional, far-se-á também uma primeira análise do Projeto Amigos da Escola, no sentido de tentar desmistificar os interesses e pretensões nele implícitos.

O projeto Amigos da Escola teve início em 1999, como uma iniciativa da Rede Globo de Televisão, que o desenvolveu juntamente com o Projeto Brasil 500 Anos e o Comunidade Solidária. Destina-se a fortalecer a participação comunitária no esforço de melhoria da escola pública, com o lema Amigos da escola todos pela educação.

Conforme informações constantes no site do Projeto Amigos da Escola, este apresenta dois objetivos principais que são subdivididos em objetivos específicos:

- contribuir com a educação pública fundamental, por meio da mobilização da sociedade para o exercício da responsabilidade social;

- fortalecer a formação e a organização de ações voluntárias para colaborar com a educação pública, interagindo com diretores, professores e funcionários das escolas.

Pelos dois grandes objetivos propostos pelo Projeto, pode-se confirmar que as políticas educacionais neoliberais estão nele explícitas, pois implicitamente se propõem a não intervenção estatal na educação pública e a isenção de responsabilidades do Estado por ela. Na medida em que se conclama a sociedade civil para a resolução de um problema que é mais grave do que aparenta, está-se isentando-o de sua culpa. Por isso, afirma-se que não há falta de investimentos, que há recursos suficientes para a gestão eficaz das escolas públicas; que os professores são qualificados e aptos para o exercício profissional de qualidade; que as escolas possuem boa infraestrutura para funcionamento; que não há falta de profissionais para conduzir eficazmente ${ }^{8}$ as atividades pedagógicas e administrativas, entre outras.

O Projeto pretende contemplar como objeto de atuação as 60.478 escolas públicas de Ensino Fundamental do Brasil que possuem Associação de Pais e Mestres (APM), visando a: estimular as escolas a abrirem suas portas para a comunidade; convocar a sociedade brasileira a participar de ações de voluntariado; e ampliar as parcerias entre sociedade e escola, na tentativa de aproximar a comunidade da vida escolar. De forma pretensiosa e ambiciosa, o Projeto pretende contribuir para a melhoria da escola e consequentemente, do desempenho dos alunos. 
O caráter ambicioso e pretensioso do projeto está posto no sentido de ter como objeto de atuação um universo extremamente amplo e abranger todo o território nacional. E, mais ainda, de atribuir toda a responsabilidade pela solução de problemas históricos da educação nacional à sociedade civil, como se esta fosse, sozinha, resolver os problemas e melhorar a qualidade da educação brasileira. Se houvesse fórmulas mágicas para a resolução de problemas históricos gravíssimos de forma imediata, será que o problema já não se teria resolvido há mais tempo?

Ainda conforme as informações contidas no site do Projeto "Amigos da Escola", este foi elaborado e planejado para atuar em seis linhas de ação:

- gestão escolar - são desenvolvidas atividades complementares aos serviços que exerçam influência direta na qualidade da gerência da escola e no atendimento integral ao aluno;

- instalações e equipamentos - são desenvolvidas atividades que visam melhorar a estrutura física das escolas por intermédio de serviços de reforma, manutenção, ampliações e limpeza;

- reforço escolar - são desenvolvidas atividades complementares ao ensino, tanto na escola como fora dos bancos escolares, com o intuito de melhorar o rendimento escolar dos alunos e reduzir os índices de repetência;

- estímulo à leitura - são desenvolvidas atividades destinadas a desenvolver nos alunos o gosto pela leitura, que pode ser obtido com a criação e dinamização de bibliotecas, dramatizações;

- artes e esportes - são desenvolvidas atividades que visam valorizar e fortalecer a identidade cultural das cidades e regiões onde as escolas atuam, e podem ser atingidas através da organização de mostras culturais, torneios e campeonatos;

- saúde e qualidade de vida - são desenvolvidas atividades que visam melhorar as condições de vida e de saúde do aluno e de sua família, que podem ser obtidos através do atendimento médico, orientação familiar e preservação do meio ambiente.

Com essas seis linhas de ação, pode-se notar que a intenção dos idealizadores do projeto é retirar a total responsabilidade do governo pela manutenção da educação nacional e repassá-la à sociedade civil. Além disso, vislumbra-se de forma explícita a tentativa de denegrir a imagem do profissional da educação, como se este fosse o principal responsável pelo fracasso da escola pública, pelos altos índices de evasão escolar, pela falha na aprendizagem, entre outros. Ou seja, o professor é tido como o principal 
responsável por todas as mazelas da educação nacional. Outro questionamento a ser feito: se o professor que é o profissional qualificado para atuar na escola pública não está conseguindo responder aos constantes e crescentes desafios contemporâneos, segundo os seguidores do neoliberalismo, como se pode supor que cidadãos que não possuem qualificação específica para atuação na escola possam resolver tão graves problemas com apenas algumas horas de dedicação voluntária?

O que se quer destacar nessa análise preliminar do Projeto Amigos da Escola não é que a sociedade não pode participar e não deva participar ativamente das atividades das escolas públicas. O que não se pode admitir é o que se está fazendo: jogar toda a responsabilidade pela melhoria da educação nacional nas costas da sociedade. É óbvio que o papel a ser desempenhado pelo voluntário pode contribuir de forma significativa para a melhoria da escola pública. Entretanto, o Poder Público precisa fazer sua parte e de forma eficaz.

A estrutura institucional do Projeto é constituída da seguinte forma:

- coordenação nacional;

- núcleos regionais em todas as regiões do país, coordenados por representantes da TV Globo e das Emissoras Afiliadas, em parceria com Secretarias de Educação, ONG, Universidades, e outras instituições públicas e privadas. Alguns coordenadores de núcleos são também responsáveis pela articulação do voluntariado interno da TV Globo, que conta com funcionários de diversas funções.

Pela configuração da estrutura institucional do Projeto, pode-se perceber que o número de pessoas envolvidas é grande e que o planejamento estratégico de ações é vinculado à cúpula organizacional da Rede Globo deTV.

A operacionalização do Projeto ocorre primeiramente pela adesão espontânea das escolas interessadas por meio do site do Projeto. Num segundo momento, as escolas cadastradas recebem os materiais de apoio e se organizam para trabalhar com parceiros e voluntários. Entende-se por materiais de apoio um kit com sete fascículos, que fornecem as orientações básicas para o desenvolvimento do trabalho.

Pelo que se percebe, há uma ampla e ótima estrutura que fornece as condições necessárias para a operacionalização do Projeto Amigos da escola.

Os participantes do Projeto podem ser divididos em dois grandes grupos:

- as escolas públicas de Ensino Fundamental;

- os voluntários. 
Tabela I - Numero de escolas participantes do Projeto

\begin{tabular}{|c|c|c|c|}
\hline Estado & $\begin{array}{c}\text { Escolas } \\
\text { Participantes } \\
\text { em } 2001\end{array}$ & $\begin{array}{c}\text { Escolas } \\
\text { Participantes } \\
\text { em } 2004\end{array}$ & $\begin{array}{c}\text { Crescimento do } \\
\text { número de escolas } \\
\text { no Projeto }\end{array}$ \\
\hline Bahia & 5.672 & 5.816 & 144 \\
\hline São Paulo & 2.604 & 2.858 & 254 \\
\hline Minas Gerais & 2.603 & 2.840 & 237 \\
\hline Paraná & 2.538 & 2.678 & 140 \\
\hline Goiás & 1.286 & 1.387 & 101 \\
\hline Rio de Janeiro & 1.255 & 1.402 & 147 \\
\hline Rio Grande do Sul & 1.240 & 1.345 & 105 \\
\hline Ceará & 1.129 & 1.205 & 76 \\
\hline Santa Catarina & 858 & 990 & 132 \\
\hline Pará & 636 & 694 & 58 \\
\hline Pernambuco & 604 & 681 & 77 \\
\hline Paraíba & 532 & 615 & 83 \\
\hline Maranhão & 494 & 551 & 57 \\
\hline Espírito Santo & 435 & 486 & 51 \\
\hline Rio Grande do Norte & 422 & 438 & 16 \\
\hline Rondônia & 404 & 413 & 09 \\
\hline Mato Grosso do Sul & 380 & 408 & 28 \\
\hline Amazonas & 349 & 355 & 06 \\
\hline Alagoas & 313 & 323 & 10 \\
\hline Piauí & 282 & 301 & 19 \\
\hline Mato Grosso & 280 & 333 & 53 \\
\hline Tocantins & 276 & 296 & 20 \\
\hline Distrito Federal & 276 & 326 & 50 \\
\hline Sergipe & 249 & 264 & 15 \\
\hline Amapá & 92 & 95 & 03 \\
\hline Acre & 66 & 75 & 09 \\
\hline Roraima & 58 & 59 & 01 \\
\hline Total & 25.328 & 27.234 & 1.906 \\
\hline
\end{tabular}

Fonte: Projeto Amigos da Escola

Os dados disponíveis no site do Projeto apresentam apenas os números relativos ao quantitativo de escolas participantes, mas não ao de voluntários. Também não são fornecidas informações sobre o universo de escolas existentes em cada Estado. Isso demonstra que não há uma clareza 
nas informações fornecidas no site do Projeto, talvez para tentar abafar o pequeno interesse da população pelo mesmo.

Pela tabela I, pode-se verificar que, em seis anos de atividade, o Projeto Amigos da Escola conseguiu atrair a participação de menos de $50 \%$ do total das escolas que eram seu público-alvo. No segundo ano de funcionamento do Projeto haviam cadastradas $41,87 \%$ das escolas públicas de Ensino Fundamental possíveis e, três anos mais tarde, esse percentual cresce para 45,03 , ou seja, um crescimento de pouco mais de $3,15 \%$. Se considerarmos os investimentos feitos em propaganda, esse valor é insatisfatório. Se nos estivéssemos referindo a uma organização com fins lucrativos, teríamos que rever nossas estratégias de marketing e os instrumentos de divulgação utilizados.

$\mathrm{O}$ aumento em mais de três anos de divulgação intensa com toda certeza não atingiu os resultados esperados pelos promotores do Amigos da escola, pois o valor gasto em propaganda foi muito alto em relação ao crescimento do número de participantes. Pois, nos três primeiros anos de implantação do Projeto, a Rede Globo de Televisão apresentava diariamente, em vários horários, no mínimo vinte incursões diárias de trinta segundos. Ou seja, um investimento altíssimo em propaganda, comparado ao das grandes organizações, tais como: Casas Bahia (o maior investidor em propaganda na TV no Brasil), as empresas do setor alimentício, as cervejarias, as grandes redes de supermercados, as instituições financeiras, as montadoras, entre outros. Importante destacar que o dois maiores investidores em propaganda na TV são as próprias emissoras de TV, fazendo propaganda de seus programas, e o poder público, em todos os âmbitos e níveis.

Num segundo momento, além das incursões na programação diária da TV, houve também a inclusão de um quadro no Fantástico, programa em horário nobre da Rede Globo, aos domingos à noite. Nesse programa, há a apresentação de iniciativas denominadas atividades de sucesso desenvolvidas por voluntários em escolas públicas. Portanto, há a tentativa de, por meio da mídia, incentivar a população a participar ativamente do Projeto e, com isso, tornar-se famoso, aparecendo na televisão e, também, de ser importante para a tão apregoada qualidade da escola pública. Uma mera ilusão, da forma como está sendo conduzida.

O que se pode concluir é que, mesmo com ampla e pesada divulgação, o Amigos da Escola não atingiu os resultados esperados em termos de participação, pois o investimento foi muito grande em relação ao retorno. 


\section{CONSIDERAÇÕES FINAIS}

Nessa breve e preliminar análise do Projeto Amigos da Escola destacaram-se como pontos a serem cuidadosamente refletidos:

- apesar de o projeto estar em seu sexto ano de atuação e do grande poder de persuasão da mídia, em especial da Rede Globo, o número de escolas participantes no projeto ainda é pequeno, atingindo 45,03\% das escolas-alvo;

- o projeto se insere nas propostas educacionais neoliberais, que tendem a transformar a instituição escolar numa empresa lucrativa;

- a tentativa do Estado de isentar-se de suas obrigações, repassando à comunidade a responsabilidade pelo funcionamento e manutenção da escola pública;

- a tentativa de privatização da escola pública, sob o argumento da falta de qualidade e do alto custo em relação ao benefício que proporciona à população;

- e por fim, a tentativa de denegrir a imagem dos profissionais da educação que atuam nas escolas públicas, bem como de sua necessidade e função nas instituições escolares públicas, com a conclamação do cidadão para suprir as funções daqueles profissionais.

Dessa maneira, o que se pode observar com a implantação de Projetos como esse, igualmente a tantos outros, propostos durante as décadas de 1980 e 1990, é a tentativa do Poder Público de isentar-se de suas responsabilidades com a educação nacional, conclamando a sociedade civil a colaborar com a manutenção e o desenvolvimento do Ensino Fundamental, especificamente.

A questão da solidariedade e do chamamento da sociedade para a resolução dos problemas da educação nacional não é coisa nova na educação brasileira, pois esteve presente em algumas das Cartas Constitucionais brasileiras. Isso pode ser observado nas Constituições de 1934, 1937, 1946, 1967 e 1969, que já previam que "a educação, inspirada no princípio da unidade nacional e nos ideais de liberdade e solidariedade humana, é direito de todos e dever do Estado" Portanto, quando se invocou o princípio da solidariedade humana, estava implícita a divisão de responsabilidades entre a sociedade e o poder público.

Já a Constituição de 1988 vai além e formaliza essa corresponsabilidade pela educação nacional, ao regulamentar, em seu artigo 205, que a educação, direito de todos e dever do Estado e da família, será promovida e incentivada com a colaboração da sociedade, visando ao pleno desenvolvimento da pessoa, seu preparo para o exercício da cidadania e sua qualificação para o trabalho. 
SOLIDARITY AND EDUCATION: A PRELIMINARY ANALYSIS OF THE 'FRIENDS OF THE SCHOOL'FROM THE VIEWPOINT OF NEOLIBERAL EDUCATIONAL PROPOSALS.

ABSTRACT: The aim of this paper is to present a preliminary discussion on the 'Friends of the School Project'. Begun in 1999 and operating for six years, it is the result of an initiative taken by the Globo Television Network which has been directing it along with the projects 'Brazil 500 Years on' and the Solidarity Community. It was set up to encourage community participation in order to improve public schools. This preliminary analysis sets out to question and reflect on three issues which fan out into a number of other extremely important issues, considered essential to understanding the hegemonic neoliberal project which has formed around the theme of solidarity associated with educational issues: the attempt of the State to renege on its obligations and leave the community responsible for the operation and maintenance of public schools; the attempt to privatize public school on the grounds of their poor quality and high running costs as compared with the benefits provided; and, the attempt to tarnish the image of educational professionals working in public schools, to question the need for and functions of these schools and call on society to compensate for what is wanting in these professionals.

KEYWORDS: Neoliberalism and Education. Friends of the School Project. School quality.

\section{NOTAS}

1. O pensamento liberal é constituído por um conjunto de princípios, apresentando como premissas básicas a defesa da economia de mercado, a liberdade da iniciativa econômica e a limitação do Estado, tanto em relação aos seus poderes (Estado de direito) quanto às suas funções (Estado mínimo). O pensamento liberal ou - como é tradicionalmente conhecido - o liberalismo clássico perdurou, enquanto ideologia dominante, até a segunda década do século XX, quando se verificou a estruturação dos fundamentos teóricos do Estado de Bem-Estar Social, os quais viriam a se consolidar como proposta hegemônica após a Segunda Guerra Mundial. A condição sine qua non para que os ideais da proposta ideológica do Estado do Bem-Estar Social vingassem e se espalhassem pela Europa e pelo mundo encontram-se na crise estrutural do modelo de acumulação fordista. O pensamento liberal, enquanto doutrina política e econômica, surgiu no século XVIII, em oposição às monarquias absolutas e contra o mercantilismo, e teve seu apogeu no século XIX.

2. A Escola Austríaca do pensamento econômico ou Escola de Viena, como também ficou conhecida, fundamentava suas análises na teoria da utilidade marginal do valor subjetivo. Essa teoria associa todos os fenômenos econômicos às ações dos indivíduos. Entre os principais economistas desta escola, destacam-se: Carl Menger, Eugen von Böhn-Bawerk, Ludwig von Mises e Friedrich A. Hayek. 
3. O professor Ludwig von Mises (1881-1973), principal porta-voz da Escola Austríaca, nasceu em Lemberg, antigo império Austro-Húngaro. Formado em Direito e Economia pela Universidade de Viena, foi aluno e seguidor do economista Carl Menger, e recebeu o título de Doutor em Economia na Universidade de Viena em 1906. É considerado um dos responsáveis pelo renascimento do pensamento liberal após a Segunda Guerra Mundial. Entre seus livros mais importantes, encontram-se The Theory of Money and Credit (1912), Human Action (1949) e Theory and History (1957). No Brasil, o Instituto Liberal é o responsável pela publicação e tradução de suas obras. Seu trabalho mais conhecido foi Liberalismo: segundo a tradição clássica, publicado pela primeira vez em 1927. Nela explica o que era a doutrina liberal, tratando criteriosamente os fundamentos do liberalismo e analisando os conceitos inerentes a essa doutrina.

4. Friedrich August von Hayek (1899-1992) nasceu na Áustria e foi discípulo de Mises. Estudou na Universidade de Viena, tendo recebido o título de Doutor em Direito e Ciências Políticas. Lecionou, inicialmente, na Universidade de Viena. Naturalizou-se inglês, e, em 1950, transferiu-se para a Universidade de Chicago. Em 1974 recebeu o Prêmio Nobel de Economia. Hayek, um dos idealizadores da proposta ideológica neoliberal, ficou conhecido por seu livro "O caminho da Servidão", publicado em 1944 na Inglaterra. A obra, que pode ser considerada o "manual do neoliberalismo", apresenta uma crítica ao processo de intervenção estatal na economia de mercado. Escrita às vésperas das eleições inglesas de 1945, sua intenção foi a de tentar demonstrar que as propostas sociais e o Programa de Governo apresentados pelo Partido Trabalhista eram inviáveis e prejudicariam o desenvolvimento do país. No prefácio de seu livro declara que o estudo então apresentado é de caráter político e não de cunho filosófico social, portanto, não discute de forma direta questões sociais. Desse modo, seu trabaIho é uma minuciosa análise do estado, à época, do Governo inglês e do avanço do socialismo, enquanto modelo político em ascensão, advertindo os riscos e problemas que a sociedade como um todo e os indivíduos, em especial, estariam correndo, de perder seus direitos adquiridos com o liberalismo - a perda da liberdade em todos os níveis. Expunha que os perigos do socialismo já haviam sido esclarecidos nas obras de Alexis de Tocqueville e Lord Acton, ou seja, o estado socialista representava uma séria ameaça para a liberdade individual e conduzia à servidão.

5. A Escola de Chicago era composta por um grupo de economistas que entendem que os mercados concorrenciais, livres da intervenção do Estado, levam ao funcionamento mais eficiente da Economia. Entre os economistas da Escola de Chicago podemos destacar: Milton Friedman, Knight, Stigler, Henry e Gary Becker, que defendem um papel reduzido para o Estado.

6. Outro grande defensor das idéias neoliberais é Milton Friedman, nascido em Nova York, em 1912. Cursou economia na Universidade de Rutgers em New Brunswick, onde terminou seus estudos em 1932. Seguidor dos ideais de Adam Smith concluiu seu curso de Mestrado em 1933, na Universidade de Chicago, sofrendo influência de economistas como Frank Knight, Wesley C. Mitchell e Harold Hotelling. Defendeu sua tese de doutorado em 1939, e em 1946 transferiu-se para a Universidade de Chicago 
para ministrar aulas. Seus principais trabalhos foram Capitalismo e Liberdade (1962) e A monetary history of the United States (1968). Suas teorias econômicas exerceram influência no Governo de Richard Nixon e, em 1976, recebeu o Prêmio Nobel de Economia. Seu pensamento econômico está fundamentado na defesa do laissez-faire e o mercado livre em todos os níveis da economia, inclusive o internacional. Enfatiza a liberdade como objetivo último a ser atingido e o indivíduo como principal ator da sociedade.

7. O Estado de Bem-Estar Social (Welfare State) ou - como também ficou conhecido - o Estado assistencialista, estava pautado pelo princípio de proporcionar e garantir as condições mínimas de renda, alimentação, saúde, habitação e educação a todos os cidadãos, enquanto um direito político adquirido. $O$ papel a ser desempenhado pelo Estado refere-se ao de tentar conciliar interesses distintos; de um lado, os interesses da classe trabalhadora, e de outro, os interesses do capital. As bases teóricas do Estado de Bem-Estar Social se consolidaram na Europa em 1947, sendo a Grã-Bretanha a primeira nação a adotar suas políticas.

8. Shigunov Neto, Teixeira e Campos (2005) afirmam que o termo eficaz deriva do latim efficace e significa aquilo que produz o efeito desejado. Em termos organizacionais, pode-se definir a eficácia como sendo a forma de gerenciar determinada atividade de modo a maximizar os recursos disponíveis, ou seja, é a forma de realizar determinada tarefa da melhor maneira possível, levando em conta os objetivos e o resultado a ser atingido. Eficácia é fazer certo as coisas certas, ou fazer as coisas certas, do modo certo e no tempo certo. Já o termo eficiência deriva do latim efficientia e significa a virtude de produzir um efeito. Em termos organizacionais pode-se definir a eficiência como sendo a forma de gerenciar determinada atividade de modo a apenas realizar a atividade pré-determinada. Ou seja, eficiência significa fazer certo as coisas.

\section{REFERÊNCIAS}

AZEVEDO, M. L. N. Neoliberalismo e educação: novo conflito entre o público e o privado. 1995. 118 f. Dissertação (Mestrado em Educação) - Universidade Federal de São Carlos, São Carlos, 1995.

CARRION, R. K. M.; VIZENTINI, P. G. F. (orgs.) Globalização, neoliberalismo, privatizações: quem decide este jogo? Porto Alegre: Editora da Universidade/UFRGS, 1997.

COMBLIN, J. O neoliberalismo: ideologia dominante na virada do século. 3.ed. Petrópolis: Vozes, 2001.

ESTÊVÃO, C. A. V. Globalização, metáforas organizacionais e mudança organizacional: dilemas e desafios. Porto: Edições Asa, 2002.

. O público e o privado em educação - a providenciação pública do privado na educação portuguesa. In: PACHECO, J. A. (org.) Políticas educativas: o neolibralismo em educação. Porto, Porto Editora, 2000. p. 135-59. 
. Redescobrir a escola privada portuguesa como organização: na fronteira da sua complexidade organizacional. Braga, Editora da Universidade do Minho, 1998.

FRIEDMAN, M. Capitalismo e liberdade. 2.ed. São Paulo: Nova Cultural, 1985.

GENTILI, P. A. A. (org.). Pedagogia da exclusão: crítica ao neoliberalismo em educação. 6. ed. Petrópolis: Vozes, 2000.

. Adeus à escola pública: a desordem neoliberal, a violência do mercado e o destino da educação das maiorias. In: . (Org.). Pedagogia da exclusão: crítica ao neoliberalismo em educação. 6. ed. Petrópolis: Vozes, 2000. p. 228-52

. Neoliberalismo e educação: manual do usuário. In: ; SILVA, T. T. (orgs.). Escola S.A. Quem ganha e quem perde no mercado educacional do neoliberalismo. 2. ed. Brasília: CNTE, 1999, p. 9-49.

. A falsificação do consenso: simulacro e imposição na reforma educacional do neoliberalismo. Petrópolis: Vozes, 1998.

.; SILVA, T. T.. (orgs.). Neoliberalismo, qualidade total e educação: visões críticas. 8. ed. Petrópolis: Vozes, 1999.

HAYEK, F. A. O caminho da servidão. 5. ed. Rio de Janeiro: Instituto Liberal, 1990.

PACHECO, J. A. (org.) Políticas educativas: o neolibralismo em educação. Porto: Porto Editora,2000.

PASSET, René. A ilusão neoliberal. Rio de Janeiro: Record, 2002.

PROJETO AMIGOS DA ESCOLA. Disponível em: <http://www.amigosdaescola.com. br>. Acesso em 20 de maio de 2001

SADER, E.; GENTILI, P. (orgs.) Pós-neoliberalismo: as políticas sociais e o Estado democrático. Rio de Janeiro: Paz e Terra, 1995.

SANTOMÉ, J. T. A educação em tempos de neoliberalismo. Porto Alegre: Artmed, 2003.

SHIGUNOV NETO, A.. História da educação brasileira: do período colonial ao predomínio das políticas educacionais neoliberais. Rio de Janeiro: Ciência Moderna, 2011 (no prelo).

;MACIEL, L. S. B.. As políticas neoliberais e a formação de professores: propostas de formações simplistas e aligeiradas em épocas de transformações. In: (orgs.). Formação de professores: passado, presente e futuro. São Paulo: Cortez, 2004.

;TEIXEIRA, A. A.; CAMPOS, L. M. F. Fundamentos da Ciência Administrativa. Rio de Janeiro: Ciência Moderna, 2005.

SILVA, T. T.; GENTILI, P. (orgs.). Escola S.A. Quem ganha e quem perde no mercado educacional do neoliberalismo. 2. ed. Brasília: CNTE, 1999. 
AleXANDRe Shigunov Neto é administrador, mestre em Educação, autor de livros de Administração, Turismo e Formação de Professores. É diretor de Pesquisa e Extensão da Faculdade Central de Cristalina (FACEC)

Email: shigunov@gmail.com

Lizete Shizue Bomura Maciel é mestre e doutora em Educação pela Pontifícia Universidade Católica de São Paulo (PUC/SP), líder do Grupo de Estudos e Pesquisas em Trabalho Docente e Aprendizagem Escolar - GEPAE, da Universidade Estadual de Maringá (UEM), professora do Programa de Pós-Graduação em Educação da UEM.

Email:newliz@uol.com.br 
